\title{
Intervention Delivery Matters: What Mothers at High Risk for Type 2 Diabetes Want in a Diabetes Prevention Program-Results from a Comparative Effectiveness Trial
}

\author{
Kelly N. B. Palmer (D) - Valene E. Garr Barry • David G. Marrero • \\ Brett M. McKinney · Anne N. Graves · Chelsy K. Winters • \\ Tamara S. Hannon
}

Received: June 26, 2020 / Published online: August 8, 2020

(C) The Author(s) 2020

\section{ABSTRACT}

Participants in the ENCOURAGE Healthy Families Study, a family-focused, modified Diabetes Prevention Program, reported challenges to and preferences for engaging in a diabetes prevention program. Challenges with flexible intervention delivery, accessibility, the traditional group-based format, and Coronavirus Disease 2019 (COVID-19) exposure risk can be mitigated by participant preferences for one-on-one, virtual/online intervention delivery.

Trial Registration: ClinicalTrials.gov identifier, NCT01823367.

Digital Features To view digital features for this article go to https://doi.org/10.6084/m9.figshare.12656225.

K. N. B. Palmer $(\bowtie)$ • D. G. Marrero •

B. M. McKinney

Department of Medicine, Indiana University School

of Medicine, Indianapolis, USA

e-mail: kpalmer1@arizona.edu

\section{E. Garr Barry}

Department of Nutrition Sciences, University of Alabama, Birmingham, AL, USA

\section{A. N. Graves · C. K. Winters}

YMCA of Greater Indianapolis, Indianapolis, USA

T. S. Hannon

Department of Pediatrics, Indiana University School of Medicine, Indianapolis, USA
Keywords: COVID-19; Gestational diabetes; Lifestyle intervention; Type 2 diabetes; Prediabetes; Primary prevention

\section{Key Summary Points}

Why carry out this study?

Current diabetes prevention programs (DPPs) struggle with engaging vulnerable, high-risk populations, such as low-income mothers with a history of gestational diabetes or prediabetes.

How can we adapt diabetes prevention programming to effectively address the needs and preferences of the most critical stakeholders-the patients while taking into consideration the current COVID-19 pandemic?

\section{What was learned from the study?}

Mothers at high risk for type 2 diabetes mellitus need flexible intervention attendance options.

Mothers at high risk for type 2 diabetes mellitus prefer one-on-one intervention sessions over the traditional group DPP format as well as virtual programming.

Virtual diabetes prevention programming is responsive to patients' needs and preferences and the COVID-19 pandemic. 


\section{INTRODUCTION}

The Diabetes Prevention Program (DPP) has been proven to be safe, effective, and sustainable across a broad range of populations, including those in vulnerable communities with the highest risk for type 2 diabetes mellitus (T2D) [1]. Unfortunately, many evidence-based risk reduction programs, such as the DPP, suffer from high attrition and low adherence due to rigid program structure $[2,3]$. The recent challenges related to coronavirus disease 2019 (COVID-19) and the fear of person-to-person disease transmission [4, 5] further limits the feasibility of traditional intervention delivery. Hence, there is a pressing need to consider alternative methods to deliver diabetes interventions and to understand their effect on the most critical stakeholders, namely, patients. Therefore, in this report we present the challenges to participation and preferences for intervention delivery for women who were predominantly low-income enrolled in a modified DPP.

\section{METHODS}

The ENCOURAGE Healthy Families (ENCOURAGE) study enrolled women with at least one child (aged 8-15 years) who were overweight or obese and had histories of either gestational diabetes mellitus (GDM) and/or prediabetes. ENCOURAGE utilized a 16-week group-based DPP approach in which participants were randomized to attend weekly sessions either alone or in parallel with their children at local Young Men's Christian Association (YMCA) locations [6]. Participants were surveyed to elicit preferences for intervention delivery.

This study received approval from the Indiana University Institutional Review Board. All participants provided consent or assent. Parents consented for themselves and their participating children. Children provided assent. This study was performed in accordance with the Helsinki Declaration of 1964 and its later amendments (ClinicalTrials.gov identifier NCT01823367).
For this report, descriptive statistics and frequencies were calculated for self-reported demographics and socioeconomic variables along with diabetes risk factors (e.g., body mass index [BMI], hemoglobin A1c [HbA1c]) and measures of intervention participation (e.g., number of sessions attended and absences). We identified questions addressing participant preferences for a diabetes prevention intervention from an exit survey administered to ENCOURAGE participants. Questions allowed multiple responses and provided an option to include other (i.e., not listed) responses. The prevalence of each response was compared (1) between completers (attended $\geq 8$ classes) and non-completers (attended $<8$ classes) and (2) by intervention randomization using Fisher's exact chi-square test. Analyses were performed using SAS statistical software version 9.4 (SAS Institute, Cary, NC, USA), and statistical significance was predetermined as $p<0.05$.

\section{RESULTS}

A total of 79 participants provided survey responses regarding their preferences and intervention engagement. Baseline characteristics are detailed in Table 1 . At baseline, mean ( \pm standard deviation) age of the participants was $39 \pm 12$ years; mean BMI was $37.5 \pm 6.9$ (range $22.4-62.4) \mathrm{kg} / \mathrm{m}^{2} ; 89.9 \%$ of participants had a $\left.\mathrm{BMI}>30 \mathrm{~kg} / \mathrm{m}^{2}\right)$; and mean HbA1c was $5.6 \% \pm 0.3$ (30.4\% with HbA1C > 5.7\%). Participants predominantly self-identified as African American (60.8\%) and European American (32.9\%). There were no significant differences in baseline characteristics by intervention completion status or randomization group. Table 2 summarizes the attendance of survey respondents. Overall, half of participants did not attend intervention sessions. Only $13.5 \%$ completed the intervention. Table 3 shows that lack of time $(36.4 \%)$ and scheduling conflicts (35.1\%) were the most cited challenges to attendance and engagement in the intervention. The group-based format also posed a challenge, with $37.2 \%$ being unable to commit to a day/time/location that worked for others. Regarding alternative intervention delivery 
Table 1 Baseline characteristics of mothers who completed the exit survey for the ENCOURAGE diabetes prevention study $(N=79)$

\begin{tabular}{|c|c|}
\hline Baseline characteristics & Values \\
\hline \multicolumn{2}{|l|}{ Demographics } \\
\hline Age (years) & $\begin{array}{r}39.6 \pm \\
11.6\end{array}$ \\
\hline Ethnicity (\% Hispanic or Latina) & 11.4 \\
\hline \multicolumn{2}{|l|}{ Race (\%) } \\
\hline African American (Black) & 60.8 \\
\hline European American (White) & 32.9 \\
\hline Other & 6.9 \\
\hline \multicolumn{2}{|l|}{ Marital status (\%) } \\
\hline Married & 43.0 \\
\hline Divorced & 21.5 \\
\hline Separated & 6.33 \\
\hline Never married & 17.7 \\
\hline Living with partner & 7.6 \\
\hline \multicolumn{2}{|l|}{ Education level (\%) } \\
\hline $\begin{array}{l}\text { High school graduate, GED credential or } \\
\text { lower }\end{array}$ & 20.5 \\
\hline Some college, or 2-year college degree & 38.5 \\
\hline 4-year college graduate & 28.2 \\
\hline$>4$-year college degree & 12.8 \\
\hline \multicolumn{2}{|l|}{ Work/employment status (\%) } \\
\hline Employed or full-time student & 84.9 \\
\hline Unemployed, disabled, or other & 15.1 \\
\hline \multicolumn{2}{|l|}{ Income level (\%) } \\
\hline$<\$ 25,000$ & 25.6 \\
\hline$>\$ 25,000$ but $<\$ 35,000$ & 15.4 \\
\hline$>\$ 35,000$ but $<\$ 50,000$ & 20.5 \\
\hline$>\$ 50,000$ but $<\$ 75,000$ & 15.4 \\
\hline$>\$ 75,000$ & 16.7 \\
\hline Refused to answer; don't know & 5.4 \\
\hline \multicolumn{2}{|l|}{ Number of children (\%) } \\
\hline 1 & 24.7 \\
\hline
\end{tabular}

Table 1 continued

\begin{tabular}{ll}
\hline Baseline characteristics & Values \\
\hline 2 & 33.8 \\
3 & 19.5 \\
$\geq 4$ & 22.1 \\
Diabetes risk factors & \\
BMI $\left(\mathrm{kg} / \mathrm{m}^{2}\right)$ & $37.3 \pm 7.8$ \\
BMI $>30 \mathrm{~kg} / \mathrm{m}^{2}$ & 89.9 \\
Hemoglobin Alc (\%) & $5.7 \pm 0.3$ \\
Alc $>5.7 \%$ & 30.4 \\
\hline
\end{tabular}

Values are presented as the mean \pm standard deviation or as a percentage

There were no significant differences between ENCOURGAGE Study respondents and non-respondents $B M I$ Body mass index, GED General Education Development, HbAlc hemoglobin Alc (glycated hemoglobin)

methods and motivations, flexible attendance options (39.2\%), more time and location options (31.7 and 27.9\%, respectively), and ability to change attendance options (20.0\%) were commonly preferred, as shown in Table 4 . At least half of the participants preferred having access to online or virtual content. Interestingly, $17.7 \%$ noted one-on-one sessions would help them stay engaged while $47.7 \%$ said being successful at weight loss would help them stay motivated.

\section{DISCUSSION}

Poor adherence and high attrition remain significant challenges for DPPs targeting persons in high-risk communities, particularly for parents with competing priorities [7]. ENCOURAGE, a youth-friendly DPP curriculum, was delivered to mothers with increased risk for T2D at local YMCAs [6]. However, like other studies, participation and engagement were met with challenges. These challenges with program participation mirror recent reports from the 
Table 2 Intervention participation of mothers who completed the exit survey for the ENCOURAGE diabetes prevention study $(\mathrm{N}=79)$

\begin{tabular}{lc}
\hline $\begin{array}{l}\text { Intervention participationof mothers who } \\
\text { completed the exit survey }\end{array}$ & Values \\
\hline Intervention assignment & 56.1 \\
Mom-only group (\%) & 46.8 \\
Mom and child(ren) group (\%) & $6.7 \pm$ \\
Attendance & 5.4 \\
Classes attended & $5.1 \pm$ \\
& 3.4 \\
Class absences & \\
Number of classes attended (\%) & 50.6 \\
0 & 3.8 \\
1 & 15.2 \\
$2-4$ & 7.6 \\
$5-7$ & 13.9 \\
\hline
\end{tabular}

Values are presented as the mean \pm standard deviation or as a percentage

There were no significant differences between ENCOURGAGE Study respondents and non-respondents

National Diabetes Prevention Program of low retention rates for younger and racial minority populations [8]. Based on survey results, three themes emerged that can inform future delivery of diabetes prevention interventions: flexibility, accessibility, and group-based format.

The combination of scheduling conflicts and the lack of alternative program delivery modes create a perfect storm for non-engagement. The lack of flexible attendance options prevents participation in this program, especially by parents actively raising children. DPPs targeted to low-income mothers and other high-risk populations must address participant burden and opportunity costs.

Over half of participants reported wanting online or virtual sessions. The DPP has been translated into digital formats to increase
Table 3 Mothers' responses to questions regarding perceived challenges to intervention attendance and engagement with comparison by intervention completion status and group randomization $(N=79)$

\begin{tabular}{|c|c|c|}
\hline $\begin{array}{l}\text { Responses to } \\
\text { specific questions } \\
\text { regarding perceived } \\
\text { challenges to } \\
\text { intervention } \\
\text { attendance and } \\
\text { engagement }\end{array}$ & $\begin{array}{l}\text { Percentage of } \\
\text { those who } \\
\text { chose } \\
\text { response }\end{array}$ & $\begin{array}{l}\text { Percentage who } \\
\text { indicated } \\
\text { response is/was } \\
\text { most important }\end{array}$ \\
\hline
\end{tabular}

"What challenges did you face to attend the YMCA classes? $^{\text {? }}$

Responses related to flexibility

Too busy/do not 36.4

have enough time

Changes in my $\quad 35.1 \quad 23.0$

family's schedule

Demands at work $15.6 \quad 9.5$

They were too
time-consuming

$11.4^{\mathrm{b}}$

Sick kids

$1.3^{\mathrm{c}}$

Responses related to accessibility

$\begin{array}{lll}\text { Lack of childcare } & 9.1 & 2.7 \\ \text { Lack of } & 2.6^{\mathrm{b}} & 2.7 \\ \text { transportation } & & \\ \text { Unreliable } & 2.6^{\mathrm{b}} & 2.7 \\ \text { transportation } & & \\ \text { Cost of } & 3.9 & 0.0 \\ \text { transportation } & & \end{array}$

Responses related to motivation

$\begin{array}{lll}\text { Lacking } & 16.9^{c} & 4.1 \\ \text { motivation/desire } & & \\ & \end{array}$

to attend

"What are some challenges of the group format of the YMCA classes for you and your family?”

Responses related to flexibility 
Table 3 continued

\begin{tabular}{|c|c|c|}
\hline $\begin{array}{l}\text { Responses to } \\
\text { specific questions } \\
\text { regarding perceived } \\
\text { challenges to } \\
\text { intervention } \\
\text { attendance and } \\
\text { engagement }\end{array}$ & $\begin{array}{l}\text { Percentage of } \\
\text { those who } \\
\text { chose } \\
\text { response }\end{array}$ & $\begin{array}{l}\text { Percentage who } \\
\text { indicated } \\
\text { response is/was } \\
\text { most important }\end{array}$ \\
\hline
\end{tabular}

I am unable to 37.2
commit to a
day/time/location
that works for
others
Responses related to group-based delivery
I do not like 11.4
talking to/in front
of people I do not
know
Sometimes I feel
judged by others
Not enough time
to talk about
things that are
important to me
I do not feel l can 2.5
voice my personal
opinion in a group

There were no differences in response selections between mothers that were randomized to attend sessions alone versus attending sessions with parallel classes for children YMCA Young Men's Christian Association

${ }^{a}$ Responses are sorted in order of most important within response theme

$\mathrm{b} \chi^{2}$ test indicates response was more frequently reported by intervention non-completers $(<8$ sessions) than intervention completers ( $\geq 8$ sessions), $p<0.05$

c $\chi^{2}$ test indicates response was more frequently reported by intervention completers ( $\geq 8$ sessions) than intervention non-completers ( $<8$ sessions), $p<0.05$
Table 4 Mothers' responses to questions regarding preferred alternative intervention delivery methods and motivations with comparison by intervention completion status and group randomization $(N=79)$

\begin{tabular}{ll}
\hline Mothers' responses to questions & \% who chose \\
regarding preferred alternative & response \\
intervention delivery methods and & \\
motivations & \\
\hline
\end{tabular}

"Are there other ways of delivering the YMCA classes that would be easier for your family to attend? ${ }^{a}$

Responses related to flexibility

Flexible attendance options (ability

to go to different locations, days, or

times on a drop-in basis)

More program time options

Having more location options

(church, school, housing complex, community center, library,

grocery/drug store, etc.)

Responses Related To Accessibility

Online/web-based sessions

Video/virtual sessions with a coach

(Skype, FaceTime, etc.)

Text message/email alerts

Video/DVD package for classes

Phone based

Responses related to group-based delivery

One-on-One

"What would motivate you to attend the YMCA classes regularly even when your schedule made it challenging to do so?"

Responses related to flexibility

Ability to alter/change up location or $20.0^{\mathrm{b}}$

day/time

Responses related to group-based delivery

Getting a motivating $5.3^{\mathrm{b}}$ message/hearing from one of my group members 
Table 4 continued

\begin{tabular}{|c|c|}
\hline $\begin{array}{l}\text { Mothers' responses to questions } \\
\text { regarding preferred alternative } \\
\text { intervention delivery methods and } \\
\text { motivations }\end{array}$ & $\begin{array}{l}\text { \% who chose } \\
\text { response }\end{array}$ \\
\hline $\begin{array}{l}\text { Hearing about the successes of my } \\
\text { group }\end{array}$ & 5.3 \\
\hline Responses related to motivation & \\
\hline Being successful at weight loss & $47.7^{\mathrm{b}}$ \\
\hline $\begin{array}{l}\text { Getting a motivating } \\
\text { message/hearing from my coach/ } \\
\text { leader }\end{array}$ & 16.0 \\
\hline $\begin{array}{l}\text { Recognition/incentives for } \\
\text { accomplishments (attendance, } \\
\text { reaching goals, etc.) }\end{array}$ & 6.7 \\
\hline
\end{tabular}

There were no differences in response selections between mothers that were randomized to attend sessions alone versus attending sessions with parallel classes for children

a Responses are sorted in order of most important within response theme

b $\chi^{2}$ test indicates response was more frequently reported by intervention non-completers $(<8$ sessions $)$ than intervention completers ( $\geq 8$ sessions), $p<0.05$

accessibility and cost-effectiveness [9-11]. However, the dissemination of such formats has been limited for those who may benefit most from DPP interventions due to persistent beliefs that low-income Americans have limited access to technology (e.g., computers, internet, and smartphones).

The ENCOURAGE intervention was delivered in a group setting, to allow for an economy of time and resources, as well as to facilitate the sharing of knowledge and points of view of fellow participants. However, women reported a preference for one-on-one sessions. One-on-one sessions could mitigate participants' feeling uncomfortable or judged. Also, one-on-one sessions would resolve scheduling issues of a group-based model. A recent pilot study of veterans with prediabetes who attended individualized lifestyle counseling sessions delivered one-on-one by medical providers showed promising results in reducing A1c levels [12].
It is important to note a few limitations of the current study, including low engagement and low intervention completion rate. The survey response rate was $61.7 \%$, potentially resulting in selection bias. However, there were no significant differences in baseline characteristics between respondents and non-respondents. Also, the survey was developed for this study and was not validated, which could introduce response bias due to measurement error. While the results may not be generalizable, they do provide practical implications for diabetes prevention programming in "realworld" settings.

In light of the current COVID-19 pandemic, consideration must be given to minimizing risk of exposure for those with and at high risk for T2D. Offering one-on-one, online/virtual programming not only addresses the preferences for tailored engagement, but also reduces risk of exposure for both participants and DPP staff. Online/virtual delivery of family-based diabetes prevention interventions can expand access while also addressing preference for one-on-one sessions and the need for flexible attendance options.

\section{CONCLUSION}

In conclusion, the demands required for participation in evidence-based diabetes prevention interventions in socioeconomically vulnerable populations, youth, and families are prohibitively high and limit the effectiveness of these programs in the community. Lower personal demands for participation in programs and flexible program attendance options designed to prevent diabetes will be required.

\section{ACKNOWLEDGMENTS}

The authors would like to recognize the support and participation of the lifestyle intervention coaches of the YMCA of Greater Indianapolis, the staff of the Indiana University School of Medicine Diabetes Translational Research Center, and the involvement of all ENCOURAGE study participants. 
Funding. This work was supported by the JPB Foundation, New York, NY and the IUPUI Signature Center Initiative Fund. Sponsors did not contribute to the writing of this report or in the decision to submit the article for publication. The Journal's Rapid Service Fee is funded by the University of Arizona Health Sciences Center for Border Health Disparities.

Authorship. All named authors meet the International Committee of Medical Journal Editors (ICMJE) criteria for authorship for this article, take responsibility for the integrity of the work as a whole, and have given their approval for this version to be published.

Disclosures. Kelly NB Palmer, Valene Garr Barry, David G Marrero, Brett M McKinney, and Tamara S Hannon have nothing to disclose. Anne Graves and Chelsey Winters are employees of the YMCA of Greater Indianapolis. Kelly N. Palmer and David G Marrero are currently affiliated with University of Arizona Health Sciences.

Compliance with Ethics Guidelines. This study received approval from the Indiana University Institutional Review Board. All participants provided consent or assent. Parents consented for themselves and their participating children. Children provided assent. This study was performed in accordance with the Helsinki Declaration of 1964 and its later amendments (ClinicalTrials.gov identifier NCT01823367).

Data Availability. The datasets generated during and/or analyzed during the current study are available from the corresponding author on reasonable request.

Open Access. This article is licensed under a Creative Commons Attribution-NonCommercial 4.0 International License, which permits any non-commercial use, sharing, adaptation, distribution and reproduction in any medium or format, as long as you give appropriate credit to the original author(s) and the source, provide a link to the Creative Commons licence, and indicate if changes were made. The images or other third party material in this article are included in the article's Creative Commons licence, unless indicated otherwise in a credit line to the material. If material is not included in the article's Creative Commons licence and your intended use is not permitted by statutory regulation or exceeds the permitted use, you will need to obtain permission directly from the copyright holder. To view a copy of this licence, visit http:// creativecommons.org/licenses/by-nc/4.0/.

\section{REFERENCES}

1. The Diabetes Prevention Program (DPP) Research Group. The Diabetes Prevention Program (DPP). Diabetes Care. 2002;25(12):2165-71.

2. Johnson M, Jones R, Freeman C, et al. Can diabetes prevention programmes be translated effectively into real-world settings and still deliver improved outcomes? A synthesis of evidence. Diabet Med. 2013;30:3-15.

3. Whittemore R. A systematic review of the translational research on the Diabetes Prevention Program. Transl Behav Med. 2011;1:480-91.

4. Harper CA, Satchell LP, Fido D, Latzman RD. Functional fear predicts public health compliance in the COVID-19 pandemic. Int J Mental Health Addict. 2020. https://doi.org/10.1007/s11469-02000281-5

5. Ornell F, Schuch JB, Sordi AO, Kessler FHP. "Pandemic fear" and COVID-19: mental health burden and strategies. Braz J Psychiatry. 2020;43(3):232-35. https://doi.org/10.1590/1516-4446-2020-0008.

6. Hannon TS, Carroll AE, Palmer KN, Saha C, Childers WK, Marrero DG. Rationale and design of a comparative effectiveness trial to prevent type 2 diabetes in mothers and children: The ENCOURAGE healthy families study. Contemp Clin Trials. 2015;40:105-11.

7. Burnet DL, Plaut AJ, Wolf SA, et al. Reach-out: a family-based diabetes prevention program for African American youth. J Natl Med Assoc. 2011;103: 269-77.

8. Cannon MJ, Masalovich S, Ng BP, et al. Retention among participants in the National Diabetes Prevention Program Lifestyle Change Program, 2012-2017. Diabetes Care. 2020. https://doi.org/10. 2337/DC19-2366. 
9. Kramer MK, Kriska AM, Venditti EM, et al. A novel approach to diabetes prevention: evaluation of the Group Lifestyle Balance program delivered via DVD. Diabetes Res Clin Pract. 2010;90:e60-3.

10. McTigue KM, Conroy MB, Hess $\mathrm{R}$, et al. Using the internet to translate an evidence-based lifestyle intervention into practice. Telemed e-Health. 2009;15:851-8.
11. Tate DF, Jackvony EH, Wing RR. Effects of Internet behavioral counseling on weight loss in adults at risk for type 2 diabetes: a randomized trial. JAMA. 2003;289:1833-6.

12. Dorcely B, Bergman M, Tenner C, Katz K, Jagannathan R, Pirraglia E. Manhattan veterans affairs medical center diabetes prevention clinic. Clin Diabetes. 2020. https://doi.org/10.2337/cd19-0085. 